\title{
Evaluation of Resistance to the Aphid (Aphis glycines Matsumura) in Soybean Cultivars and Germplasms
}

\author{
Myung Sik Kim, Mi Kyung Sung, Woon Jang Baek, Min Hwan Kim, and Jong II Chung \\ Department of Agronomy, Research Institute of Life Science, Gyeongsang National University, JinJu 660-701, Korea,
}

\begin{abstract}
Native of soybean aphid (Aphis glycines Matsumura) is an Asia and aphid is one of the dangerous pests in soybean [Glycine max (L.) Merr.]. High density aphid populations can reduce crop production by causing severe damage. The objective of this study was evaluation of resistance to the soybean aphid in soybean cultivars and germplasms. A total of fifty five soybean cultivars or germplasms, including two susceptible and two resistant check varieties, were infested to evaluate their resistance in the field cage and greenhouse test by aphid colonies which derived from wild collected one soybean aphid biotype in Korea.

The average number of reproduced soybean aphid was evaluated with 62.7 aphids in the resistant check variety PI 567598B and also estimated with 1,807 aphids for susceptible check variety Williams 82. In soybean varieties and germplasms, the average reproduced soybean aphid populations ranged from the lowest 497 aphids for Junjeori to the highest 3,862 aphids for Mansu. About seventy six percent of soybean cultivars and germplasms were shown high density soybean aphid populations when compared with another susceptible check variety PI 567543C in the field cage test. From the greenhouse test to evaluate aphid index, $87.3 \%$ of soybean cultivars or germplasms presented aphid index with 9.0. No soybean cultivars and germplasms were observed with soybean resistant phenotype when regarded a aphid resistant level as less than $10 \%$ aphid reproductions compared with susceptible check Williams 82 .

Although no Korean soybean cultivars were identified with resistant trait to the soybean aphid, we found one great resistant genetic resource PI 567598B in this study. This result will be helpful to further study for providing useful genetic information for soybean researchers.
\end{abstract}

Keywords : aphid index, Rag, Soybean aphid, Korean soybean cultivar

Soybean [Glycine max (L.) Merr.] is one of the important crops for human food and animal feed in worldwide. The soybean aphid (Aphis glycines Matsumura) is native to Asia, including China, Korea, Japan, Russia, Philippines, Indonesia, Malaysia, Thailand, Australia, and Vietnam (Fletcher and Desborough 2000; Wu et al., 2004). This pest was first discovered in eight Midwestern U.S. states in 2000 (Hartman et al., 2001). It was detected 21 U.S. states and 3 Canadian provinces by 2003 (Venette and Ragsdale, 2004) and has become one of the major economic pests affecting soybean production in North America. Soybean aphid populations can double very quickly (Mccornack et al., 2004), because female soybean aphids can reproduce female aphid asexually and produce live young (viviparous) to increase its population to adapt in favorable environments (Takahashi et al., 1993). On the supercooling point of $-34^{\circ} \mathrm{C}$, eggs are well-adapted for surviving in cold winters (Mccornack et al., 2005). The feeding activity of high density aphid populations can reduce soybean production directly during growing season (Hartman et al., 2001). Aphid feeding reduces photosynthesis by causing growth of black sooty mold fungus produced by aphid honey (Macedo et al., 2003) and also reduces yield components, plant height, stunting, withered flower, seed size, number of nodes and pods per plant, and seed quality (Wang et al., 1962; He et al., 1991; Ostlie, 2001; DiFonzo and Hines, 2002). When early vegetative stage soybean plants are colonized by soybean aphid, yield loss in excess of 50\% can occur (Wang et al., 1994). From the feeding process soybean aphid is capable of transmitting soybean mosaic virus, soybean stunt virus, soybean dwarf virus, and the other many kinds of viruses.

Management options for this pest are limited for minimizing soybean plant damages. Growing the resistant soybean

\footnotetext{
${ }^{\dagger}$ Corresponding author: (Phone) +82-55-772-1872 (E-mail) jongil@gnu.ac.kr

$<$ Received 24 August, 2012; Revised 23 October, 2012; Accepted 6 November, 2012>
} 
varieties including aphid resistant gene Rag (Resistance to Aphis glycines) and specialist natural enemies, lady beetles, green lacewings, and other beneficial insects eat aphids in soybean field. If soybean aphid populations are significantly increasing, insecticides application will be needed to reduce soybean plant damages. Growing the aphid resistant cultivars in the field is a very helpful way to the farmers. To develop aphid resistant soybean cultivars, germplasm screening is one of the important steps for soybean breeders in their breeding programs. The resistant soybean germplasms has been identified by many research groups, Hill et al. (2004) discovered the aphid resistant germplasms Dowling (PI 548663), Jackson (PI 548657), and PI 71506. Also, Mensah et al. (2005) identified the aphid resistant germplasms PI 567543C, PI 567597C, PI 567541B, and PI 567598B. The other soybean germplasms, PI 243540, PI 567301B, and PI 567324 were resistant to the aphid (Mian et al., 2008). Soybean aphid resistant gene ragl from the genetic studies with PI 548663 and PI 548657 was located on the soybean chromosome 7 (Li et al., 2007). The rag2 gene was fine mapped on soybean chromosome 13 from PI 200538 by Kim et al. (2010). In Korea, although soybean damages caused by soybean aphid have not been observed severely so far, aphid population density could be increase by agricultural climate changes. However, not enough research papers about aphid resistant cultivars have been published currently in Korea. The objective of this study was evaluation of resistance to the soybean aphid in soybean cultivars and germplasms.

\section{MATERIALS AND METHODS}

\section{Plant materials}

A total fifty five soybean cultivars and germplasms were obtained from Gyeongsangnam-do Agricultural Research \& Extension Services or Gyeongsang National University. The other plant materials, Williams 82 and PI 642768 for soybean aphid susceptible check varieties, PI $567543 \mathrm{C}$ and PI 567598B for soybean aphid resistant check varieties, were received from USDA-ARS Plant Germplasm Inspection Station, Beltsville, MD, USA(http://www.ars-grin.gov/npgs/).

\section{Aphid culture}

Soybean aphid biotype was wild collected on Lee 74 soybean plant on mid of April 2012 at the Gyeongsang National University experiment field, Jinju city, Gyeongsangnam-do, Korea. Colonization of soybean aphid was conducted from one adult aphid using a host soybean plant Williams 82 which previously have been used as susceptible check variety, into the square aluminum box cage $(1.2 \mathrm{~m} \times 1.0$ $\mathrm{m} \times 0.8 \mathrm{~m}$ ) covered with ASTM (American Society for Testing and Materials) standard stainless steel mesh (No.100) in the greenhouse. Water provided as needed from bottom holes only to avoid losing the aphid colonies from host plants during aphid culturing stages. When aphid colonies reached enough numbers for infestation, they were used for aphid test.

\section{Cage test in the field}

Five seeds in each entry was planted into the soil directly with $30 \mathrm{~cm} \times 40 \mathrm{~cm}$ plant row distance in the cage $(2.5 \mathrm{~m}$ $\times 4.5 \mathrm{~m} \times 2.0 \mathrm{~m})$. The two cages were made with plastic mesh (no.100) to perform soybean aphid test on June 2012. After seed germination, three seedling plants remained by cutting off extra germinated plants for infestation of aphid to the three soybean plants in each cage 1 and cage 2 . The aphid colonies were infested with similar size five adult aphids using tweezers carefully to avoid damaging a aphid by transferring activities on the plant leaf surface in each entry on VC vegetative growth stage (Fehr and Caviness, 1977). The three plants were sampled after two weeks late from soybean aphid infestation date using a bypass pruner, and then saved in the plastic zipper lock. To prevent additional aphid colony reproductions, sampled plants were kept in the deep freezer with $-33^{\circ} \mathrm{C}$ temperature condition, and then it was counted the number of increased aphid colonies to know their resistance to the soybean aphid biotype.

\section{Greenhouse test}

One additional aphid test was performed to confirm resistance to aphid and was evaluate again aphid index by infestation of aphid colonies in fifty five soybean varieties and germplasms, two resistant check varieties, and two susceptible check varieties from June to July 2012 in the 
greenhouse. The greenhouse $(3.0 \mathrm{~m} \times 7.0 \mathrm{~m} \times 2.5 \mathrm{~m})$ was covered with $40 \%$ shading curtain on the top area to prevent over temperature. The other parts of greenhouse covered with plastic mesh (no.100) and water provided by bottom hole in the white display trays with no holes (Hummert international). The three seeds in each plant material were planted in randomized complete blocks using media (Chamgrow well-being, Chamgrow INC) into the 50 holes tray with randomly. After germination, some extra germinated plants were removed except one healthy plant only on the seedling stage. Two similar size aphid adults were infested on the plant leaf surface with three replications in fifty five Korean cultivars, including susceptible and resistant check varieties with three replications as described by Hill et al. (2004). After 3 weeks late from soybean aphid infestation, the soybean aphid index was calculated as described by Hill et al. (2004).

\section{RESULTS}

\section{Field test in the cage}

To evaluate aphid resistance, a total fifty five soybean cultivars and germplasms, including Williams 82, PI 642768 for susceptible check varieties and PI 567543C, PI 567598B for resistant check varieties were infested with aphid colonies in the field cage. After two weeks late from aphid infestation to the soybean plant materials, the number of increased aphid colonies from individual plant was obtained. The average number of soybean aphid colonies estimated was $1,806.5$ per plant for the standard susceptible variety Williams
82. In the PI 567598B was used for soybean aphid resistant check variety, 62.7 average number of soybean aphid colonies was observed in the experiment 1 and 2. A significant resistance was observed in the resistant check variety PI 567598B when compared with susceptible variety Williams 82 and PI 642768 (Table 1 and Figure 1-A1, 1-B1).

The average number of reproduced aphid populations ranged from the lowest 497 for Junjeori to the highest 3,862 for Mansu. No soybean variety and germplasm was observed much significant resistance than soybean aphid resistant check variety PI 567543C in the field cage experiments. The number of 1,248 aphid reproduction was observed in second resistant check variety PI 642768. Thirteen from the fifty five soybean cultivars and germplasms were shown a more resistant than PI 642768, susceptible check variety, but they still shown a high density aphid reproduction compared with resistant check variety PI 567598B. Impressively, high density soybean aphid colonies was observed in $76.4 \%$ of the soybean cultivars and germplasms when compared their resistance between resistance susceptible check variety PI 642768 and soybean cultivars and germplasms (Table 2, Figure, 2). Especially, Cheongja2\#, Heuknong51\#, Hinkongnamulkong, Gyeongsang1\#, and Mansu recorded an impressive aphid reproduction more than 3,500 aphids per plant (Table 2).

\section{Evaluation of aphid index in the greenhouse}

For the evaluation of aphid index, fifty five soybean cultivars and germplasms, two resistant check varieties, and two susceptible check cultivars were infested with two

Table 1. Reactions of soybean aphid to the susceptible and resistant check varieties in the cage and greenhouse test.

\begin{tabular}{cccccccc}
\hline \hline Check varieties & Trait & Average number of aphids /plant & \multicolumn{3}{c}{ Aphid index $^{\ddagger}$} & Average aphid index \\
\hline & & Experiment & Experiment 2 & Rep.1 & Rep.2 & Rep.3 & \\
Williams 82 & Susceptible & 1,022 & 2,592 & 9 & 9 & 9 & 9 \\
PI 642768 & Susceptible & 1,131 & 1,364 & 9 & 9 & 9 & 9 \\
PI 567543C & Resistant & 295 & 349 & 9 & 6 & 6 & 7 \\
PI 567598B & Resistant & 58 & 67 & 1 & 0 & 0 & 0.3
\end{tabular}

${ }^{\dagger}$ Five aphid adults were infested on the three plants leaf surface, and then counted a number of increased soybean aphid after two weeks late from infestation date in this study. Average number of increased aphid from six plants in each soybean aphid check variety in the experiment 1 and experiment 2.

${ }^{\ddagger}$ Aphid index was calculated by follow formula, aphid index = aphid population ( 0 , no live aphids, to 3 , high aphid density $)$ $x$ aphid damage ( 0 , no damage, to 3 , severe damage) 


\section{A1}

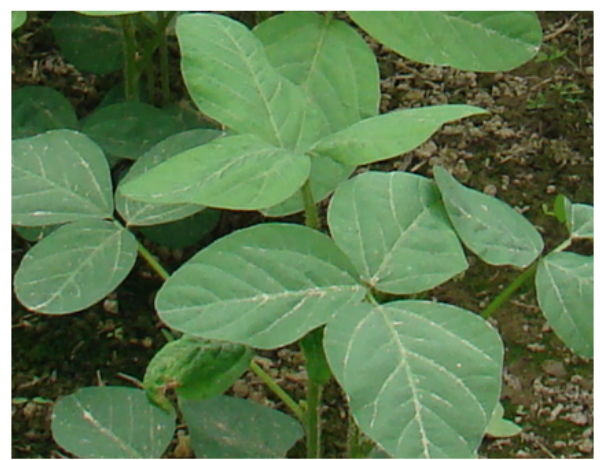

\section{A2}

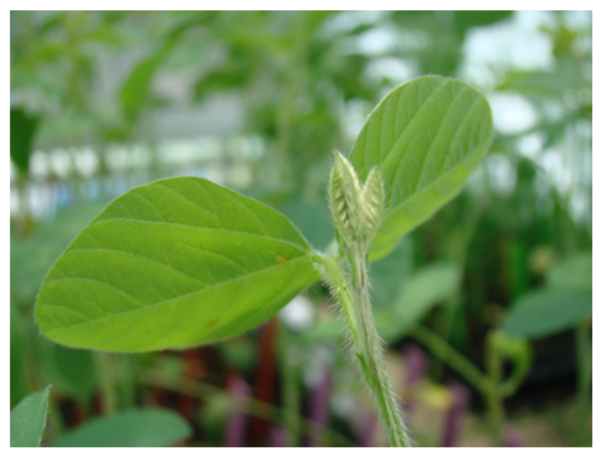

\section{B1}

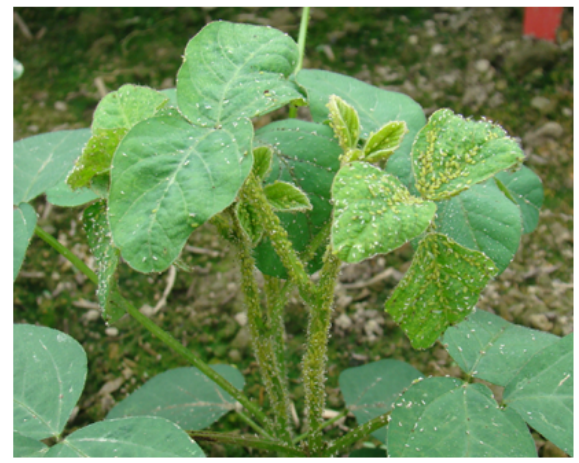

B2

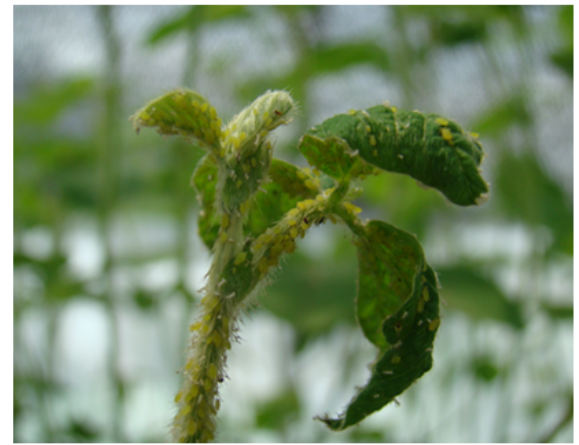

Fig. 1. Different reaction of soybean plants after two weeks late from infestation of soybean aphids in the field cage and greenhouse test. A1and A2 is soybean aphid resistant check variety PI 567598B, and B1, B2 designated susceptible check Williams 82 . The aphid test was conducted in the field cage test for A1 and B1. Another test was performed in the greenhouse for A2 and $\mathrm{B} 2$ in this study.

Table 2. Names of Cultivars and germplams, average number of aphid colonies per plant for experiment 1 and 2 in the field cage test, aphid index and average damage index in greenhouse test. (Continued)

\begin{tabular}{|c|c|c|c|c|c|c|}
\hline \multirow[t]{2}{*}{ Names of cultivars and germplasms } & \multicolumn{2}{|c|}{ Average No. of aphid /plant } & \multicolumn{3}{|c|}{ Aphid index ${ }^{\dagger}$} & \multirow{2}{*}{$\begin{array}{l}\text { Average aphid } \\
\text { index }\end{array}$} \\
\hline & Experiment 1 & Experiment 2 & Rep. $1^{\ddagger}$ & Rep.2 & Rep.3 & \\
\hline Sangwon & 573 & 480 & 9 & 9 & 9 & 9 \\
\hline Jinyang & 927 & 383 & 9 & 9 & 9 & 9 \\
\hline Galchae & 416 & 1,218 & 9 & 9 & 9 & 9 \\
\hline Cheongdu1\# & 1,210 & 427 & 9 & 9 & 9 & 9 \\
\hline Joyangkong & 790 & 869 & 9 & 9 & 9 & 9 \\
\hline Boseok & 856 & 1,244 & 9 & 9 & 9 & 9 \\
\hline Chamolkong & 1,704 & 790 & 9 & 9 & 9 & 9 \\
\hline Subaktae & 656 & 2,033 & 9 & 9 & 9 & 9 \\
\hline
\end{tabular}


Table 2. Names of Cultivars and germplams, average number of aphid colonies per plant for experiment 1 and 2 in the field cage test, aphid index and average damage index in greenhouse test. (Continued)

\begin{tabular}{|c|c|c|c|c|c|c|}
\hline \multirow[t]{2}{*}{ Names of cultivars and germplasms } & \multicolumn{2}{|c|}{ Average No. of aphid /plant } & \multicolumn{3}{|c|}{ Aphid index ${ }^{\dagger}$} & \multirow[t]{2}{*}{$\begin{array}{l}\text { Average aphid } \\
\text { index }\end{array}$} \\
\hline & Experiment 1 & Experiment 2 & Rep. $1^{\ddagger}$ & Rep.2 & Rep.3 & \\
\hline Sinhwa & 1873 & 1,060 & 9 & 9 & 9 & 9 \\
\hline Gyeongsang3\# & 1,118 & 1,895 & 9 & 9 & 9 & 9 \\
\hline Mirang & 1,272 & 1,769 & 9 & 9 & 9 & 9 \\
\hline Wonhwang & 1,737 & 1,377 & 9 & 9 & 9 & 9 \\
\hline Singi & 2,182 & 1,056 & 6 & 9 & 9 & 8 \\
\hline Daepung & 1,550 & 1,700 & 6 & 6 & 9 & 7 \\
\hline Cheongja3\# & 970 & 2,394 & 9 & 9 & 9 & 9 \\
\hline Jonam & 1,524 & 1,851 & 9 & 9 & 9 & 9 \\
\hline Uram & 2,454 & 1,160 & 9 & 6 & 9 & 8 \\
\hline Daeha & 1,694 & 2,013 & 6 & 9 & 9 & 8 \\
\hline Jinnong2\# & 982 & 2,819 & 9 & 9 & 9 & 9 \\
\hline Sohwang & 3,130 & 750 & 9 & 9 & 9 & 9 \\
\hline Daechubamkong & 1,949 & 2,025 & 9 & 9 & 9 & 9 \\
\hline Saedanbaek & 2,136 & 1,884 & 9 & 9 & 9 & 9 \\
\hline Ilpumgeomjeongkong & 2,294 & 1,763 & 6 & 9 & 6 & 7 \\
\hline Neulchan & 3,068 & 994 & 9 & 9 & 9 & 9 \\
\hline Cheongjakong & 2,955 & 1,195 & 9 & 9 & 9 & 9 \\
\hline Geomeunbapmitkong & 3,018 & 1,257 & 9 & 9 & 9 & 9 \\
\hline Buchaekong & 2,163 & 223 & 9 & 9 & 9 & 9 \\
\hline Wongwang & 3,245 & 1,158 & 9 & 9 & 9 & 9 \\
\hline Nokwon & 2,346 & 2,213 & 9 & 9 & 9 & 9 \\
\hline Cheonsang & 3,082 & 1,497 & 6 & 6 & 6 & 6 \\
\hline Socheong & 3,159 & 1,449 & 9 & 9 & 9 & 9 \\
\hline Daemang2\# & 2,954 & 1,657 & 9 & 9 & 9 & 9 \\
\hline Nampung & 1,115 & 3,658 & 9 & 9 & 9 & 9 \\
\hline Pungwon & 2,219 & 2,949 & 9 & 9 & 9 & 9 \\
\hline CJ1\# & 1,326 & 3,843 & 9 & 9 & 9 & 9 \\
\hline Gaecheok1\# & 3,028 & 2,156 & 9 & 9 & 9 & 9 \\
\hline Gyeongsang2\# & 2,029 & 3,168 & 9 & 9 & 9 & 9 \\
\hline Hinyutae & 1,304 & 3,960 & 9 & 9 & 9 & 9 \\
\hline Daeyang & 3,611 & 1,779 & 9 & 9 & 9 & 9 \\
\hline Bamkong & 3,138 & 2,424 & 9 & 9 & 9 & 9 \\
\hline Happung55\# & 3,396 & 2,291 & 9 & 9 & 9 & 9 \\
\hline Heukmi & 2,775 & 3,123 & 9 & 9 & 9 & 9 \\
\hline Bultae & 3,395 & 2,808 & 9 & 9 & 9 & 9 \\
\hline Daeheukkong & 3,162 & 3,087 & 9 & 9 & 9 & 9 \\
\hline Seomoktae & 1,945 & 4,352 & 9 & 9 & 9 & 9 \\
\hline
\end{tabular}


Table 2. Names of Cultivars and germplams, average number of aphid colonies per plant for experiment 1 and 2 in the field cage test, aphid index and average damage index in greenhouse test. (Continued)

\begin{tabular}{lcccccc}
\hline \hline Names of cultivars and germplasms & \multicolumn{2}{c}{ Average No. of aphid /plant } & & Aphid index & \multicolumn{2}{c}{$\begin{array}{c}\text { Average aphid } \\
\text { index }\end{array}$} \\
\hline & Experiment 1 & Experiment 2 & Rep. $1^{\ddagger}$ & Rep.2 & Rep.3 & \\
Cheongja2\# & 3,067 & 3,966 & 9 & 9 & 9 & 9 \\
Heuknong51\# & 3,775 & 3,427 & 9 & 9 & 9 & 9 \\
Hinkongnamulkong & 3,320 & 4,012 & 9 & 9 & 9 & 9 \\
Gyeongsang1\# & 3,789 & 3,841 & 9 & 9 & 9 & 9 \\
Mansu & 4,090 & 3,633 & 9 & 9 & 9 & 9 \\
\hline
\end{tabular}

${ }^{\dagger}$ Aphid index was calculated by follow formula, Aphid index = aphid population ( 0 , no live aphids, to 3, high aphid density) $\times$ aphid damage (0, no damage, to 3 , severe damage).

${ }^{\ddagger}$ Three plant replications were tested to estimate soybean aphid index.

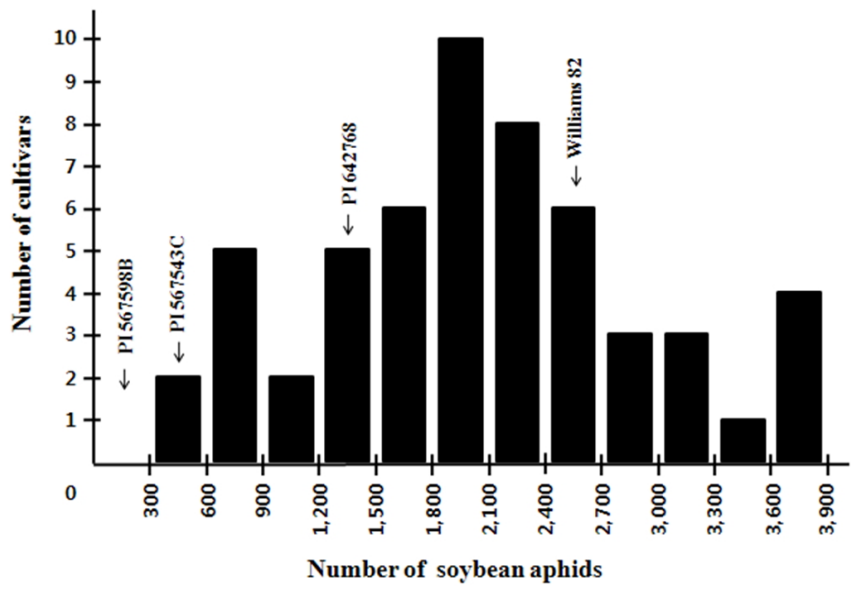

Fig. 2. Distribution of the number of soybean aphids in aphid resistant, susceptible check varieties, and 55 soybean cultivars and germplasms from the field cage tests.

adult aphids on leaf surface of individual plant in the greenhouse aphid test. The soybean aphid colonies were cultured using a susceptible host plant Williams 82 in the cage to conduct aphid greenhouse test. After three weeks from aphid infestations, the aphid index was calculated as described by Hill et al. (2004). In the susceptible check varieties, Williams 82 and PI 642768 aphid index with 9.0 were estimated and a severe plant damages by aphid sucking activities were observed. Contrastively, a resistant check soybean variety PI567598B scored with 0.3 aphid index and shown a strong resistant phenotypes in the greenhouse test (Figure 1-A2 and 1-B2). Although PI $567543 \mathrm{C}$ variety which had been used for soybean aphid resistant varieties by former soybean aphid researchers, this variety scored with 7.0 aphid index by infestation of wild soybean aphid biotype in Korea. The Socheong2\#, Daepung, and Daeha presented aphid index with 6.0, 7.0 and 8.0, respectively. They shown a high density aphid population in the field cage test compared with resistant check variety PI 567598B and PI 567543C (Table 1 and 2). Forty eight among the fifty five, $87.3 \%$, soybean varieties and germplasms were shown a high density aphid reproduction on their plant and aphid index estimated as 9.0 (Table 2). When regarded an aphid resistant levels $<10 \%$ comparing the susceptible check variety Williams 82 , these results indicated that all of the fifty five Korean soybean varieties were susceptible to the wild collected aphid biotype colonies in present studies.

\section{DISCUSSION}

The objective of this study was evaluation of resistance to wild collected soybean aphid biotype in soybean cultivars and germplasms. Two Soybean aphid tests were conducted to evaluate aphid resistance and to estimate aphid index in fifty five soybean plant materials by infestation of soybean aphid. No soybean cultivars and germplasms were shown a significant resistance to the soybean aphid compared with the two resistant check varieties PI 567543C and PI 567598B in the field cage test. In the greenhouse test, $87.3 \%$ of soybean cultivars and germplasms presented aphid index with 9.0 (Table 1 and 2). It is difficult to compare this result with the other reports directly concerning the soybean aphid 
resistant using soybean cultivars and germplasms. Chung et al. (1980) identified that the soybean aphid population density were varied in their three Korean soybean cultivars by the treatment of planting date and space in six soybean varieties including three foreign soybean cultivars. Increasing of soybean aphid population was peaked on August 18, 1978. It was estimated with 8.6, 9.7, 13.6 aphids in Chungbukbaik, Bongeui, and Kumkangdaerip, respectively. The other Korean soybean cultivar Seokrangputkong and Kwangan were used for soybean aphid test by Kim et al. (2000). In their study, two soybean aphid density peaks were observed on end of June and on middle of August 1998, aphid reproduction ranged 0 70 from June through August in 1998 in their field test. It is not easy work to compare the soybean aphid resistance and former two results.

In order to development of a new soybean cultivar, screening of genetic resistant resources is first step in breeding programs. We did one additional aphid test to find aphid resistant soybean germplasm from end of July through middle of August 2012 in the field cage at the Gyeongsang National University experimental field. A total thirteen germplasms, PI 200538, PI 243540, PI 548409, PI 548480, PI 548657, PI 548663, PI 567301B, PI 567324, PI 567541B, PI 567543C, PI 567597C, PI 567598B, and PI 71506 which previously classified with aphid resistant soybean by Hill et al. (2004, 2006, and 2008), Mensah et al. (2005, 2008), and Mian et al. (2008), were infested with same aphid colonies in this germplasm screening. Unfortunately, all the soybean aphid resistant resources were shown a susceptible phenotype to the Korean wild collected soybean aphid colonies except PI 567598B resource in present study (data not shown). In this study, although all of the fifty five soybean cultivars and germplasms were identified with susceptible phenotype to the soybean aphid, we found one significant resistant genetic resource PI 567598B from our experiment. This result will be helpful to further study for providing useful genetic information for soybean researchers.

\section{ACKNOWLEDGMENTS}

This study was supported by Technology Development Program for Agriculture and Forestry, Ministry for Food,
Agriculture, Forestry and Fisheries, Republic of Korea (Research number: 111097-03-1-SB010).

\section{REFERENCES}

Chung, K. H., S. H. Kwon, and Y. I. Lee. 1980. Studies on the density of soybean aphids in different cultivars, planting dates and spacings. J. Korean Soc. Crop Sci. $25: 3: 35-40$.

DiFonzo, C. D. and R. Hines. 2002. Soybean aphid in Michigan: Update from the 2001 season. Michigan State Univ. Ext. Bull. E-2748. Michigan State Univ., East Lansing.

Fehr, W. R. and C. E. Caviness. 1977. Stages of soybean development. Spec. Rep. 80. Iowa Agric. Home Econ. Exp. Stn., Iowa State Univ., Ames.

Fletcher, M. J. and P. Desborough. 2000. The soybean aphid, Aphis glycines, present in Australia (http://www.agric.nsw.gov.au/ Hort/ascu/insects/aglycin.htm).

Hartman, G. L., L. L. Domier, L. M. Wax, C. G. Helm, D. W. Onstad, J. T. Shaw, L. F. Solter, D. J. Voegtlin, C. J. D’Arcy, M. E. Gray, K. L. Steffey, S. A. Isard, and P. L. Orwick. 2001. Occurrence and distribution of Aphis glycines on soybeans in Illinois in 2000 and its potential control. Plant Health Prog.

He, F., Y. Fanyue, X. Wanmin, L. Xiaoping, and W. Yanquin. 1991. Optimal spraying time and economic threshold of the soybean aphid. Acta Phytopathol. Sin. 18 : 155-159.

Hill, C. B., K. Kim, L. Crull, B. W. Diers, and G. L. Hartman. 2009. Inheritance of resistance to the soybean aphid in soybean PI 200538. Crop Sci. 49 : 4 : 1193-1200.

Hill, C. B., Y. Li, and G. L. Hartman. 2004. Resistance to the soybean aphid in soybean germplasm. Crop Sci. 2004. 44 : 1 : 98-106.

Hill, C. B., Y. Li, and G. L. Hartman. 2006. Soybean aphid resistance in soybean Jackson is controlled by a single dominant gene. Crop Sci. 46 : 1606-1608.

Kim, K., C. B. Hill, G. L. Hartman, D. L. Hyten, M. E. Hudson, and B. W. Diers. 2010. Fine mapping of the soybean aphid resistance gene Rag2 in soybean PI 200538. Theoretical and Applied Genetics. 121 : 599-610.

Kim, Y. H., J. H. Roh, M. K. Kim, D. J. Im, and I. B. Hur. 2000. Seasonal occurrence of aphids and selection of insecticides for controlling aphids transmitting soybean mosaic virus. Korean J. Crop Sci. $45: 6: 353-355$.

Li, Y., C. B. Hill, S. R. Carlson, B. W. Diers, and G. L. Hartman. 2007. Soybean aphid resistance genes in the soybean cultivars Dowling and Jackson map to linkage group M. Molecular Breeding $19: 1$ : 25-34.

Macedo, B., C. S. Bastos, L. G. Higley, K. R. Ostlie, and S. Madhavan. 2003. Photosynthetic responses of soybean to soybean aphid (Homoptera: Aphididae) injury. J. Econ. Entomol. 96 : 188-193. 
Mccornack, B., D. W. Ragsdale, and R. C. Venette. 2004. Demography of soybean aphid (Homoptera: Aphididae) at summer temperatures. J. Econ. Entomol. 97 : 854-861.

Mccornack, B., M. A. Carrillo, R. C. Venette, and D. W. Ragsdale. 2005. Physiological constraints on the overwintering potential of the soybean aphid (Homoptera: Aphididae). Environmental Entomology. $34: 2$ : 235-240.

Mensah, C., C. DiFonzo, R. L. Nelson, and D. Wang. 2005. Resistance to soybean aphid in early maturing soybean germplasm. Crop Sci. 45 : 6 : 2228-2233.

Mensah, C., C. DiFonzo, and D. Wang. 2008. Inheritance of soybean aphid resistance in PI 567541B and PI 567598B. Crop Sci. 48 : 5 : 1759-1763.

Mian, M. A. R., R. B. Hammond, and S. K. Martin. 2008. New plant introductions with resistance to the soybean aphid. Crop Sci. 48 : 1055-1061.

Ostlie, K. 2001. Soybean aphid reduces yields: Harvest results from insecticide strip trials. Available at www.soybeans.umn.edu/ crop/insects/aphid/studyresults.htm (verified 12 July 2008). Univ. of Minnesota, St. Paul.

Takahashi, S. M., M. Inaizumi, and K. Kawakami, 1993. Life cycle of the soybean aphid Aphis glycines Matsusmura in Japan. Jpn. J. Appl. Entomol. Zool. 37 : 207-212.

Venette, R. C. and D. W. Ragsdale. 2004. Assessing the invasion by soybean aphid (Homoptera: Aphididae): Where will it end?. Ann. Entomol. Soc. Am. 97 : 219-226.

Wang, C. L., N. I. Xiang, G. S. Zh, and H. F. Zhu. 1962. Studies on the soybean aphid Aphis glycines Matsumura. Acta Entomol. Sin. 11 : 31-44.

Wang, X. B., Y. H. Fang, S. Z. Lin, L. R. Zhang, and H. D. Wang. 1994. A study on the damage and economic threshold of the soybean aphid at the seedling stage. Plant Prot. 20 : 12-13.

Wu, Z., D. Schenk-Hamlin, W. Zhan, D. W. Ragsdale, and G.E. Heimpel. 2004. The soybean aphid in China: A historical review. Ann. Entomol. Soc. Am. 97 : 209-218. 